\title{
The Range of Applying the Faculty Assistants for Strategies of Effective Teaching of Students of Home Economics in Faculty of Specific Education
}

\author{
Fatma Abdelrazak Omar
}

Faculty of Specific Education, South Valley University

\begin{abstract}
This study aimed to identify the extent of the application of the assistants of the members of the teaching staff at the home economics, effective teaching strategies from the face of the students, the study sample consisted of (100) of home economics students from the third and fourth grades, the study followed the Descriptive analytical method, researcher using a questionnaire to the students and the result of the study indicated. 1) The existence of statistically significant differences between the scores of students in answering the questionnaire, due to the lack of application of assistant's faculty steps each strategy the same degree of efficiency differences. 2) There were no statistically significant differences in the students answers, application for effective teaching of their point view depending on the variable of the class. 3) There were no statistically significant differences in the students answers which measures the extent of the application of effective teaching assistants staff members from their point of view depending on the specialization.
\end{abstract}

Keywords: Strategy; effective teaching; home economics ; Faculty of specific education

Citation Omar.,The Range of Applying the Faculty Assistants for Strategies of Effective Teaching of Students of Home Economics in Faculty of Specific Education. SVU-Journal of abstract 2019, Vol.1: pp18 (retrieved from the Journal of Educational Sciences; 2018, No.35; pp 271).

Copyright: Publisher South Valley University. This is an open-access article distributed under the terms of the creative commons attribution license, which permits unrestricted use, distribution and reproduction in any medium provided the original author and source are created. 